\title{
Preparation of Lipid Nanoemulsions Incorporating Curcumin for Cancer Therapy
}

\author{
Songyot Anuchapreeda, ${ }^{1,2}$ Yoshinobu Fukumori, ${ }^{2}$ Siriporn Okonogi, ${ }^{3}$ and Hideki Ichikawa ${ }^{2}$ \\ ${ }^{1}$ Division of Clinical Microscopy, Department of Medical Technology, Faculty of Associated Medical Sciences, \\ Chiang Mai University, Chiang Mai 50200, Thailand \\ ${ }^{2}$ Faculty of Pharmaceutical Sciences and Cooperative Research Center of Life Sciences, Kobe Gakuin University, \\ Minatojima 1-1-3, Chuo-ku, Kobe 650-8586, Japan \\ ${ }^{3}$ Department of Pharmaceutical Sciences, Faculty of Pharmacy, Chiang Mai University, Chiang Mai 50200, Thailand
}

Correspondence should be addressed to Hideki Ichikawa, ichikawa@pharm.kobegakuin.ac.jp

Received 17 June 2011; Revised 31 August 2011; Accepted 6 September 2011

Academic Editor: Michael M. Craig

Copyright ( $) 2012$ Songyot Anuchapreeda et al. This is an open access article distributed under the Creative Commons Attribution License, which permits unrestricted use, distribution, and reproduction in any medium, provided the original work is properly cited.

\begin{abstract}
The aim of this study was to develop a new formulation of a curcumin lipid nanoemulsion having the smallest particle size, the highest loading, and a good physical stability for cancer chemotherapy. Curcumin lipid nanoemulsions were prepared by a modified thin-film hydration method followed by sonication. Soybean oil, hydrogenated L- $\alpha$-phosphatidylcholine from egg yolk, and cosurfactants were used to formulate the emulsions. The resultant nanoemulsions showed mean particle diameter of $47-$ $55 \mathrm{~nm}$, could incorporate $23-28 \mathrm{mg}$ curcumin per $30 \mathrm{~mL}$, and were stable in particle size for 60 days at $4^{\circ} \mathrm{C}$. The cytotoxicity studies of curucumin solution and curcumin-loaded nanoemulsion using B16F10 and leukemic cell lines showed $\mathrm{IC}_{50}$ values ranging from 3.5 to 30.1 and 22.2 to $53.7 \mu \mathrm{M}$, respectively. These results demonstrated the successful incorporation of curcumin into lipid nanoemulsion particles with small particle size, high loading capacity, good physical stability, and preserved cytotoxicity.
\end{abstract}

\section{Introduction}

Curcumin (diferuloylmethane), a phenolic compound believed to be the main pharmacological agent in turmeric, possesses antioxidant activity in vitro $[1,2]$ and is used in lipid peroxidation tests [3]. Curcumin is effective for preventing and ameliorating gastric lesions. It also possesses anti-inflammatory $[4]$, antibacterial $[5,6]$, antifungal and antiyeast [7], antihypocholesterolemic [8], anticancer [9-12], antimutagen [13], antiparasitic [14], antitumorpromoting [15], antiproliferative [16], MDR modulator effects [17], and so on.

The chemical structure of curcumin isolated from turmeric powder is shown in Figure 1. Commercial-grade curcumin (such as from Sigma-Aldrich), when isolated from the powdered dry rhizome of Curcuma longa Linn, contains approximately $77 \%$ curcumin, $17 \%$ demethoxycurcumin, and 3\% bisdemethoxycurcumin. Curcumin pigments can absorb the visible light at a wavelength between $420-425 \mathrm{~nm}$.
The safety of Curcuma longa Linn and its derivatives has been studied in various animal models [18]. It has been shown that turmeric is not toxic to animals even at high doses. A single feeding of a 30\% turmeric diet to rats did not produce any toxic effects. In a 24 -h acute toxicity study, mice were fed turmeric extracts at a daily dosage of $0.5,1.0$, or $3.0 \mathrm{~g} / \mathrm{kg}$. No increase in the mortality rate was observed when compared to the respective controls. A 90-day feeding of turmeric extracts resulted in no significant weight gain [18].

The cytotoxicity of curcumin was examined using the MTT assay in cancer cell lines; Hep-2 (human larynx), PC9, PC-14 (human lung cancers), Hep-1 (mouse hepatoma), F-25 (mutate H-ras transfected NIH mouse fibroblast), and leukemic cell lines. The authors found that curcumin is a potent antiproliferative agent for the tested cancer cell lines $[19,20]$. A recent report indicates that pure curcumin concentration for oncogene target inhibition and inhibitory effect on cancer cell proliferation is $\sim 15-20 \mu \mathrm{M}$ [21]. 
<smiles></smiles>

FIGURE 1: Chemical structure of curcumin.

In order to deliver curcumin to targeted organs, its hydrophobic property needs to be modified. A wide variety of drug carriers has been studied as a mean of improving the therapeutic efficacy of drugs. The small size of carriers is very important for the biodistribution in the body. The capillaries are so small that red blood cells can only travel through them in single file. The capillaries measure approximately $5-10 \mu \mathrm{m}$ in diameter. Particles larger than this size cannot be circulated in the body and become entrapped in the capillary bed. Thus, the particle diameter should be generally smaller than micrometers for the particles to be circulated in the blood vessels. In addition, reduction in the particle diameter to less than $100 \mathrm{~nm}$ is thought to decrease their removal by the reticuloendothelial system and increase their extravasation from the smallest capillaries [22, 23]. Thus, nanotechnology is one of the effective methods to be used for the delivery of curcumin.

Many studies have been published on the production of nanoparticles to incorporate curcumin. Bisht et al. [24] proposed the polymeric nanoparticle formulation encapsulating curcumin as "nanocurcumin" for human cancer therapy. The nanocurcumin was confirmed to have a narrow particle size distribution with an average size of $50 \mathrm{~nm}$. Furthermore, nanocurcumin could induce cellular apoptosis, inhibit nuclear factor kappa $\mathrm{B}(\mathrm{NF} \kappa \mathrm{B})$, and downregulate the steady state levels of multiple proinflammatory cytokines (interleukin-(IL-) 6, IL-8, and tumor necrosis factor alpha $(\mathrm{TNF} \alpha)$ ) in pancreatic cancer cells [24]. In a recent report, curcumin was also prepared in the form of liposomes (nanodelivery vehicles primarily composed of phospholipids) coated with antibodies specific to a prostate membranespecific antigen. The coated-liposomes were approximately 100-150 nm. The liposomal curcumin showed antiproliferative activity on human prostate cancer cell lines (LNCaP and C42B) in a tetrazolium dye-based (MTT) assay [25]. Furthermore, curcumin was encapsulated in the form of alginate-chitosan-pluronic composite nanoparticles for its delivery to cancer cells. The particles were spherical in shape with an average size of $100 \pm 20 \mathrm{~nm}$. The half-maximal inhibitory concentration for encapsulated curcumin was $14.34 \mu \mathrm{M}[26]$.

Lipid emulsions have also been used as a promising drug delivery device to target tissues [27, 28]. Many studies have shown the validity of a lipid emulsion as parenteral drug delivery device [29-31]. Emulsions are heterogeneous mixtures of 2 or more immiscible liquids with an emulsifier used to stabilize the dispersed droplets. They have certain advantages such as good biocompatibility, biodegradability, physical stability, and ease of large-scale production. In addition, they can incorporate hydrophobic and amphipathic drugs because of their structural characteristics. Since curcumin has a hydrophobic nature, it can be the payload of a lipid emulsion. Thus, a lipid emulsion can be a promising device for the delivery of curcumin.

The aim of this study was to prepare curcumin in the form of a lipid emulsion with reduced particle size and increased curcumin loading. The preparation of the formulation was modified from the standard formulation of gadolinium-containing nanoemulsions described in our previous reports $[32,33]$. The effects of the type of oil and cosurfactant on particle diameter were studied. Moreover, the curcumin lipid emulsion was also evaluated on incorporation efficiency, physical stability after production, and cytotoxicity in cancer cell lines.

\section{Materials and Methods}

2.1. Chemicals. Hydrogenated L- $\alpha$-phosphatidylcholine from egg yolk (HEPC), soybean oil, polysorbate 80 (polyoxyethylene (20) sorbitanmonooleate, Tween 80), and chloroform were purchased from NacalaiTesque Inc., Kyoto, Japan. In HEPC, the phospholipid content was more than $99 \%$ and the phosphatidylcholine content was approximately $70 \%$. Lecithin from soybean was purchased from WAKO Pure Chemical Industries, Osaka, Japan. Curcumin from Curcuma Longa Linn (Turmeric) was purchased from Sigma-Aldrich, St. Louis, MO, USA. Polyoxyethylene hydrogenated castor oil 60 (Cremophor-HR60, HCO-60) was supplied by BASF, Ludwigshafen, Germany. Dimethyl sulfoxide (DMSO), 3(4,5-dimethylthiazolyl-2)-2, 5-diphenyl tetrazolium bromide (MTT) were purchased from Sigma-Aldrich (St. Louis, MO, USA). RPMI-1640 and penicillin-streptomycin were purchased from GIBCO Invitrogen (Grand Island, NY, USA). Fetal bovine serum (FBS) was obtained from Biochrom AG (Berlin, Germany). Ethanol was purchased from Fluka Chemicals (Buchs, Switzerland).

\subsection{Preparation of Curcumin-Containing Lipid Nanoemul-} sion. Curcumin-containing lipid nanoemulsions were prepared by a modified thin-film hydration method at room temperature $\left(24^{\circ} \mathrm{C}\right)$ as previously reported $[32,33]$. Briefly, the emulsions consisted of soybean oil or lecithin (phosphatidylcholine), water, curcumin, HEPC, and an appropriate co-surfactant. The oil and HEPC were dissolved in $2 \mathrm{~mL}$ of chloroform. Curcumin was dissolved in $4 \mathrm{~mL}$ of chloroform. Co-surfactant (HCO-60 or Tween 80) was dissolved in $2 \mathrm{~mL}$ of chloroform (HCO-60) or distilled water (Tween 80 ). The mixture of the 3 solutions was dried by rotary evaporation and subjected to subsequent vacuum desiccation for $3-5 \mathrm{~h}$ to generate the dried thin film. The dried thin film was hydrated with $30 \mathrm{~mL}$ of distilled water warmed at $55-60^{\circ} \mathrm{C}$ in a bath-type sonicator (BRANSON-Yamato 2510, BRANSONIC, Emerson-Japan, Kanagawa, Japan), followed by vigorous mixing and sonicating for $5 \mathrm{~min}$ to create coarse lipid emulsions. The fine lipid emulsions were prepared by 30-60 min sonication under $\mathrm{N}_{2}$ atmosphere with a bathtype sonicator, which was thermostated at $55-60^{\circ} \mathrm{C}$. The sonication was performed as follows: $3 \mathrm{~min}$ sonication and 
subsequent 2 min cooling, which were repeated for 30 $60 \mathrm{~min}$. Excess curcumin was removed by centrifugation at $3000 \mathrm{rpm}$ for $15 \mathrm{~min}$. The supernatant was collected as curcumin lipid nanoemulsion sample. Three different batches of lipid nanoemulsions were prepared with each formulation. The prepared curcumin lipid nanoemulsions were evaluated regarding particle size, curcumin concentration, and percent incorporation efficiency (\% IE) described below.

2.3. Particle Size Measurement. The particle diameter of the nanoemulsions was measured by a dynamic light scattering method using Zetasizer $3000 \mathrm{HS}_{\mathrm{A}}$ (Malvern Instrument, UK) at room temperature. Particle size data were expressed as the mean of the Z-average of 3 independent batches of the nanoemulsions.
2.4. Determination of Curcumin Concentration and Incorporation Efficiency. Curcumin in lipid nanoemulsions was quantified using a simple colorimetric assay at $450 \mathrm{~nm}$ as described previously [25]. Briefly, a standard curve was generated from known concentrations of curcumin in HBSETriton X-100 (10 mM HEPES, $140 \mathrm{mM} \mathrm{NaCl}, 4$ mM EDTA, and $1 \%$ Triton X-100). After centrifugation, $4 \mathrm{~mL}$ of HBSETriton X-100 was added to $25 \mu \mathrm{L}$ of the curcumin lipid nanoemulsion to determine the curcumin concentration in the nanoemulsion. The absorbance was measured on a spectrophotometer (UV-150-02, SHIMADZU Corporation, Japan). The amount of curcumin in the lipid nanoemulsion was calculated from the final concentration of curcumin after preparation. The curcumin incorporation efficiency (\% IE) in the lipid nanoemulsion was calculated by the following equation:

$$
\% \mathrm{IE}=\frac{(\text { Measured amount of curcumin in lipid nanoemulsion })}{(\text { Total amount of curcumin applied in preparing lipid nanoemulsion })} \times 100
$$

2.5. Solubility of Curcumin. To determine the solubility of curcumin, 3 different solutions, including soybean oil, $1.25 \%$ $(\mathrm{w} / \mathrm{v})$ Tween 80 in distilled water, and $1.25 \%$ Tween 80 with $0.83 \%$ HEPC in distilled water were tested in this study. For determining the solubility of curcumin in soybean oil, $3.5 \mathrm{mg}$ of curcumin was added to a test tube containing $1 \mathrm{~mL}$ of soybean oil. The mixture solutions were vortexed, allowed to cool, and kept at $24^{\circ} \mathrm{C}$ overnight. Thereafter, they were centrifuged at $3000 \mathrm{rpm}$ for $15 \mathrm{~min}$ at $24^{\circ} \mathrm{C}$. Undissolved curcumin, which was observed at the bottom of the test tube, was eliminated by centrifugation. Then, the amount of curcumin in soybean oil was determined by spectrophotometry at an absorbance of $450 \mathrm{~nm}$.

For determining the solubility of curcumin in the Tween 80 aqueous solutions without (Tween 80 solution) or with HEPC (Tween 80 -HEPC solution), $1.0 \mathrm{mg}$ of curcumin was added to a test tube containing $1 \mathrm{~mL}$ of the aqueous solutions, followed by vortexing. The solutions were warmed and vortexed every $5 \mathrm{~min}$ in a water bath $\left(60^{\circ} \mathrm{C}\right)$ for $1 \mathrm{~h}$. After being allowed to cool and stand at $24^{\circ} \mathrm{C}$ overnight, they were centrifuged at $3000 \mathrm{rpm}$ for $15 \mathrm{~min}$ at $24^{\circ} \mathrm{C}$. The concentrations of curcumin in the supernatant of both Tween 80 and Tween 80-HEPC solutions were measured spectrophotometrically.

2.6. Cells and Cell Culture Conditions. B16F10 (mouse melanoma cell line) was cultured in DMEM containing $10 \%$ fetal calf serum, 100 units $/ \mathrm{mL}$ penicillin, and $100 \mu \mathrm{g} / \mathrm{mL}$ streptomycin. Four types of leukemic cell lines, including HL60 (promyelocytic leukemia), K562 (chronic myelocytic leukemia), Molt4 (lymphoblastic leukemia), and U937 (monocytic leukemia), were cultured in RPMI1640 medium containing $10 \%$ fetal calf serum, $1 \mathrm{mM} \mathrm{L-}$ glutamine, 100 units $/ \mathrm{mL}$ penicillin, and $100 \mu \mathrm{g} / \mathrm{mL}$ streptomycin. These cell lines were maintained in a humidified incubator with an atmosphere of $95 \%$ air and $5 \% \mathrm{CO}_{2}$ at $37^{\circ} \mathrm{C}$. When the cells reached confluency, they were harvested and plated for consequent passages or for nanoemulsion curcumin treatments.

2.7. MTT Assay. Cell viability was determined by the MTT test method. MTT $(5 \mathrm{mg} / \mathrm{mL})$ was dissolved in PBS. B16F10 and leukemic cells were cultured in 96-well plates $\left(1.0 \times 10^{4}\right.$ and $3.0 \times 10^{3}$ cells/well, resp. $)$ containing $100 \mu \mathrm{L}$ medium prior to treatment with curcumin and curcuminloaded nanoemulsion at $37^{\circ} \mathrm{C}$ for $24 \mathrm{~h}$. Subsequently, $100 \mu \mathrm{L}$ fresh medium containing various concentrations $(4.23,8.47$, $16.97,33.93$, and $67.86 \mu \mathrm{M}$ ) of curcumin or the corresponding curcumin-loaded nanoemulsion were added to each well, and incubated for another $48 \mathrm{~h}$. Diluted curcumin solutions were freshly prepared in DMSO prior to each experiment. The final concentration of DMSO in culture medium was $0.2 \%(\mathrm{v} / \mathrm{v})$. Diluted curcumin-loaded nanoemulsion was prepared in completed RPMI-1640 medium. The curcumin concentrations from curcumin-loaded nanoemulsion were determined by the colorimetric assay as previously described [24] using the HBSE buffer containing Triton X-100. The amount of curcumin in nanoemulsion was determined by comparing to the standard curcumin curve. Then, curcumin concentrations were calculated and diluted for the equal concentrations with equimolar of conventional curcumin to test cytotoxicity by MTT assay. The nanoemulsion without curcumin was used as vehicle control. The metabolic activity of each well was determined by MTT assay and compared to those of untreated cells. After removal of $100 \mu \mathrm{L}$ medium, MTT dye solution was added $(15 \mu \mathrm{L} / 100 \mu \mathrm{L}$ medium) and the plates were incubated at $37^{\circ} \mathrm{C}$ for $4 \mathrm{~h}$ in a humidified $5 \% \mathrm{CO}_{2}$ atmosphere. After that, $200 \mu \mathrm{L}$ of DMSO were added to each well, and mixed thoroughly to dissolve the dye crystals. The absorbance was measured using an ELISA 
TABLE 1: Formulations of curcumin-loaded lipid nanoemulsion.

\begin{tabular}{|c|c|c|c|c|c|c|c|c|}
\hline \multirow{2}{*}{ Component } & \multicolumn{8}{|c|}{ Formulation } \\
\hline & 1 & 2 & 3 & 4 & 5 & 6 & 7 & 8 \\
\hline Soybean oil $(\mathrm{mL})$ & 1 & 1 & - & - & 1 & 1 & 1 & 1 \\
\hline Lecithin (mL) & - & - & 1 & 1 & - & - & - & - \\
\hline HCO-60 (mg) & - & 375 & - & 375 & - & - & - & - \\
\hline Tween 80 (mg) & 375 & - & 375 & - & 375 & 375 & 375 & 375 \\
\hline HEPC (mg) & 250 & 250 & 250 & 250 & 250 & 250 & 250 & 250 \\
\hline Curcumin (mg) & 15 & 15 & 15 & 15 & 30 & 60 & 120 & 240 \\
\hline Distilled water (mL) & 30 & 30 & 30 & 30 & 30 & 30 & 30 & 30 \\
\hline
\end{tabular}

plate reader (Biotek EL 311) at $570 \mathrm{~nm}$ with a reference wavelength of $630 \mathrm{~nm}$. High optical density readings corresponded to a high intensity of dye color, that is, to a high number of viable cells able to metabolize MTT salts. The fractional absorbance was calculated by the following formula:

$\%$ Cell survival $=\frac{\text { Mean absorbance in test wells }}{\text { Mean absorbance in control wells }} \times 100$.

The average cell survival obtained from triplicate determinations at each concentration was plotted as a dose response curve. The experiment was carried out in 3 batches of nanoemulsion preparations in 3 time-independent experiments. The $50 \%$ inhibition concentration $\left(\mathrm{IC}_{50}\right)$ of the active substances was determined as the lowest concentration which reduced cell growth by $50 \%$ in treated compared to untreated culture or vehicle control culture $(0.4 \%$ DMSO in culture medium). The $\mathrm{IC}_{50} \mathrm{~s}$ were mean \pm standard error (SE) and compared for their activities.

2.8. In Vitro Release Kinetics of Curcumin-Loaded Nanoemulsion. Curcumin-loaded nanoemulsion at the concentration of $7 \mathrm{mg}$ in $25 \%$ human serum in PBS was put into dialysis bag with pore size of $50^{\circ} \mathrm{A}(5 \mathrm{~nm})$. The dialysis bag was kept in dark bottle containing 25\% human serum in PBS with total volume of $150 \mathrm{~mL}$. The condition was controlled under constant stirring in water bath set as $37^{\circ} \mathrm{C}$. Sample $(1 \mathrm{~mL})$ was collected at certain time intervals of $2,4,6$, $12,24,36,48,60$, and $72 \mathrm{~h}$. The fresh medium was added after withdrawal. The curcumin concentration in the sample was determined by colorimetric assay measured at $450 \mathrm{~nm}$ as compared to standard curcumin as described previously [25].

2.9. Statistical Analysis. Statistical analysis was performed using the SPSS software (version 10.0). All experiments were repeated at least 3 times. The data were expressed as the mean (standard deviation and standard error; SD and SE). Statistical differences between the means were tested by oneway ANOVA. Probability values $P<0.01$ and $P<0.05$ were considered as significant.

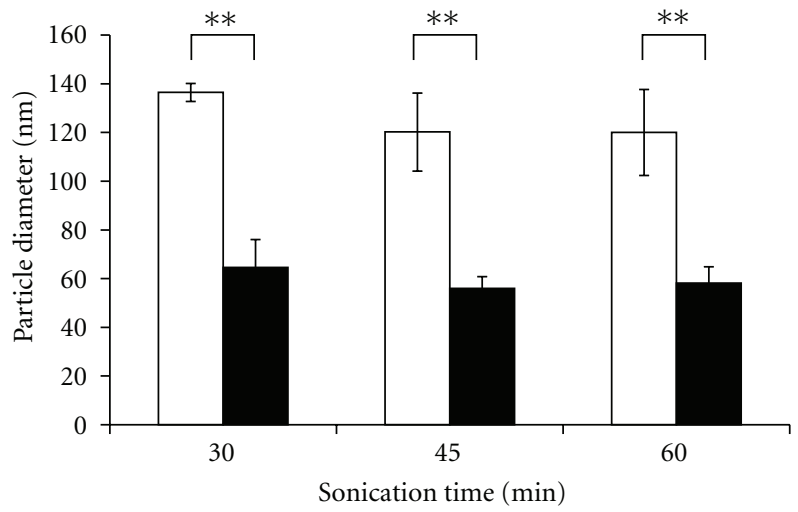

FIGURE 2: Effect of co-surfactants and sonication time on the particle diameter of curcumin-loaded lipid nanoemulsions. Closed bar: Tween 80, formulation 1. Open bar: HCO-60, formulation 2. Data are represented as the mean \pm standard deviation of 3 independent experiments $(n=3)$. ${ }^{* *}$ Significantly different from the HCO-60 formulation $(P<0.01)$ by one-way ANOVA.

\section{Results}

3.1. Formulations and Operational Factors. The formulations and preparation conditions were optimized by changing the co-surfactant type, sonication time, and oil type. First of all, in order to evaluate the effect of co-surfactant and sonication time on the mean particle diameter of lipid nanoemulsions, a series of nanoemulsions was prepared with increasing sonication times in the presence of Tween 80 (formulation 1) or HCO-60 (formulation 2; Table 1). Herein, $15 \mathrm{mg}$ of curcumin was used as the initial loading dose. In this experiment, soybean oil was used as oil component for curcumin lipid nanoemulsions.

The nanoemulsions prepared by using Tween 80 as a co-surfactant revealed the significant decrease in size as compared to HCO-60 ( $P<0.01$; Figure 2$)$. The sonication time did not result in a difference in particle diameter among the nanoemulsions prepared with different sonication times (30, 45, or $60 \mathrm{~min}$ ) in both HCO-60 and Tween 80 formulations. The mean particle diameters of lipid nanoemulsions with HCO-60 prepared with a sonication time of 30,45 , and $60 \mathrm{~min}$ were $136.5,120.2$, and $120.0 \mathrm{~nm}$, respectively, 


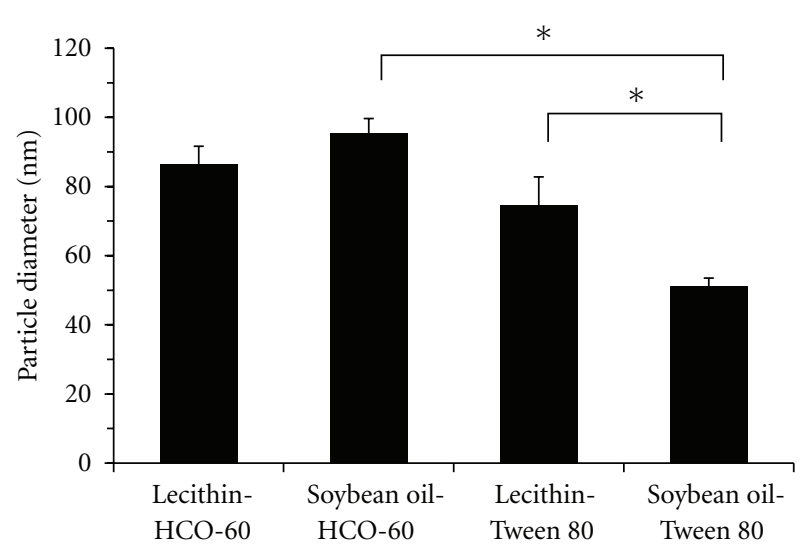

(a)

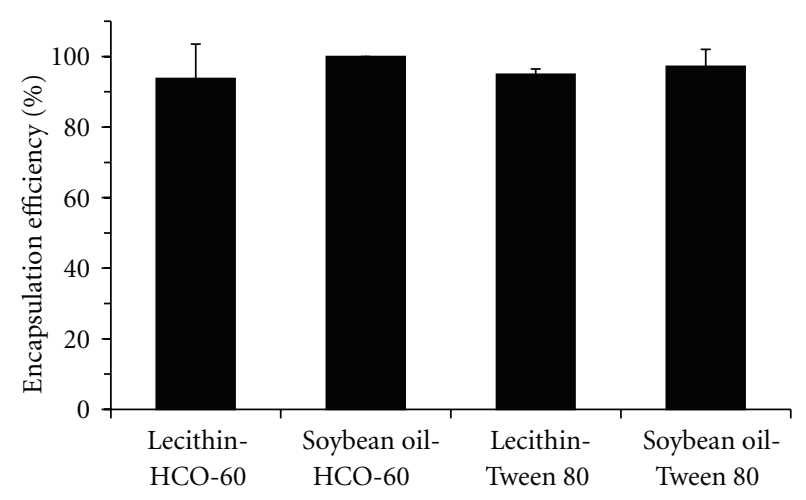

(b)

Figure 3: Effect of lipid type on the particle diameter (a) and percent incorporation efficiency (\% IE) (b) of curcumin lipid nanoemulsions. Formulation: 1, 2, 3, and 4 in Table 1. Data are represented as the mean \pm standard deviation of 3 independent experiments $(n=3)$. * Significantly different $(P<0.05)$ by one-way ANOVA.

while those with Tween 80 were $64.6,56.0$, and $58.2 \mathrm{~nm}$, respectively. The prolongation of the sonication time from $30 \mathrm{~min}$ to $45 \mathrm{~min}$ resulted only in a slight decrease in the mean particle diameter in HCO-60 and Tween 80 (11.8 and $13.9 \%$, resp.). The polydispersity indices ranged from 0.24 to 0.32 . Thus, $30 \mathrm{~min}$ of sonication was chosen for the following experiments.

3.2. Effect of Oil Type on Particle Size of Emulsion. The 4 formulations of curcumin-loaded lipid nanoemulsions in this experiment are shown in Table 1 (formulations 1-4). Curcumin nanoemulsions using soybean oil showed smaller particle sizes than those using lecithin (Figure 3(a)). The mean particle diameters of the nanoemulsions composed of soybean oil with Tween 80 and those of lecithin with Tween 80 were 51.0 and $74.6 \mathrm{~nm}$, respectively. The nanoemulsions composed of soybean oil with Tween 80 were significantly smaller in particle diameter (by 31.6\%; $P<0.05$ ) than those composed of lecithin with Tween 80 . The mean particle diameter of soybean oil nanoemulsions with Tween 80 was significantly smaller (by $46.5 \% ; P<0.05$ ) than those with

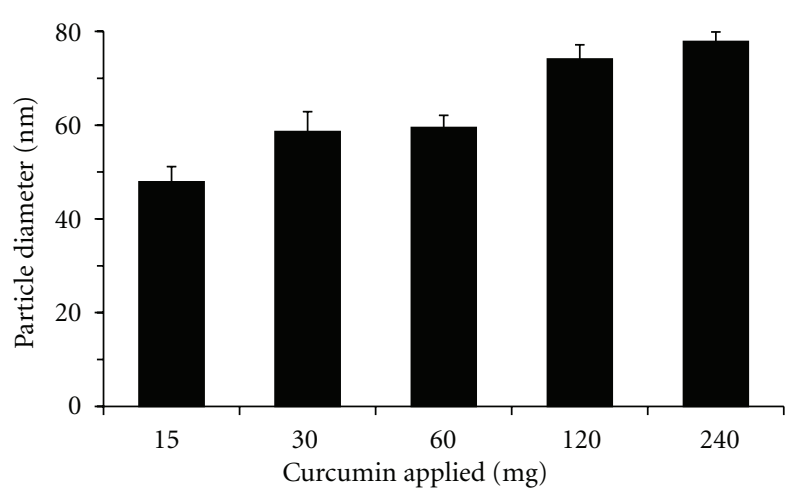

FIGURE 4: Effect of the amount of curcumin on the particle diameter of the emulsion. Formulation: 1, 5 to 8 in Table 1.

HCO-60. While the nanoemulsions composed of lecithin and soybean oil with HCO-60 did not show any significant difference in particle diameter in the statistical analysis, the polydispersity indices ranged from 0.22 to 0.37 .

Figure 3(b) shows the \% IE values of curcumin in the 4 lipid nanoemulsions prepared with formulations 1 to 4. The $\%$ IE in these 4 formulations was in the range of $93.8 \%-100 \%$. The incorporated amount of curcumin in the nanoemulsions was in the range of $14.1-15.0 \mathrm{mg}$ in total. Macroscopic observation clearly showed that free curcumin was poorly soluble in distilled water; in contrast, the prepared curcumin lipid nanoemulsions were absolutely transparent, with the hue derived from the natural color of curcumin. Furthermore, the curcumin lipid nanoemulsions with lecithin showed more transparency than those with soybean oil.

3.3. Enrichment of Curcumin in Nanoemulsions. The 5 formulations of curcumin-enriched lipid nanoemulsion are also listed in Table 1 (formulations 1, 5-8). The effects of the weight ratio of curcumin to HEPC on the mean particle diameters and particle size distributions of the emulsions are shown in Figures 4 and 5, respectively. Here, Tween 80 was used as a co-surfactant. As the amount of curcumin applied increased from $15 \mathrm{mg}$ (formulation 1) to $30 \mathrm{mg}$ (formulation 5), $60 \mathrm{mg}$ (formulation 6), $120 \mathrm{mg}$ (formulation 7), and $240 \mathrm{mg}$ (formulation 8), the particle diameter of the nanoemulsion increased from 47.9 to 58.6, $59.5,74.1$, and $77.8 \mathrm{~nm}$, respectively (Figure 4 ). When the nanoemulsions were centrifuged for separation of excess curcumin after sonication, pellets of excess curcumin could be observed when more than $30 \mathrm{mg}$ of curcumin were added, in a manner depending on the amount applied. The particle size distributions had a single peak each, with the polydispersity indices ranging from 0.22 to 0.51 (Figure 5).

When all lipid nanoemulsions were examined for \% IE after centrifugation, we found that $\%$ IE decreased depending on the amount of curcumin applied (Figure 6). However, the $\%$ IEs at 15 and $30 \mathrm{mg}$ were not significantly different. Moreover, the color of the curcumin lipid nanoemulsion exhibited no difference when more than $30 \mathrm{mg}$ of curcuminwas applied, suggesting a similar concentration of curcumin. 


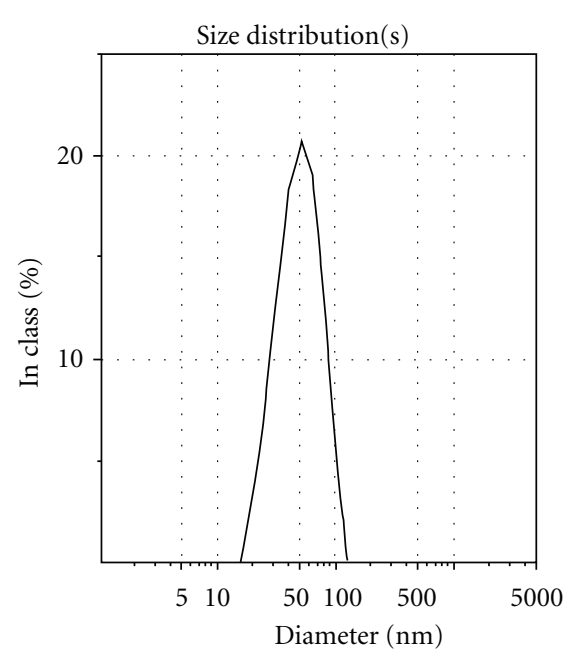

(a)

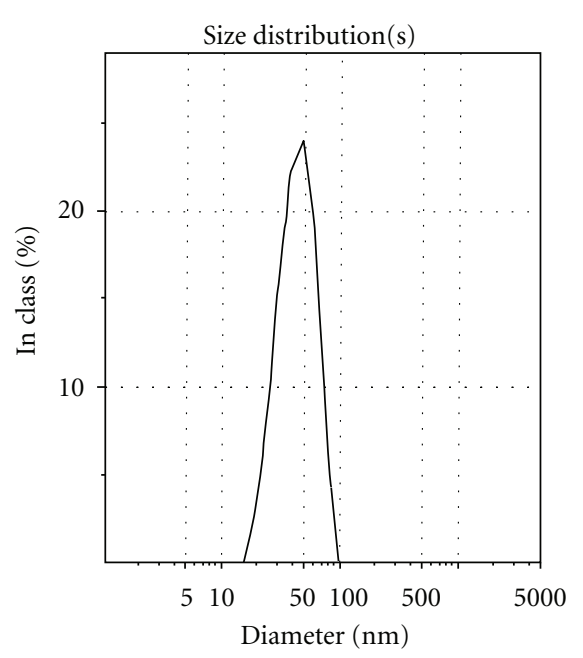

(b)

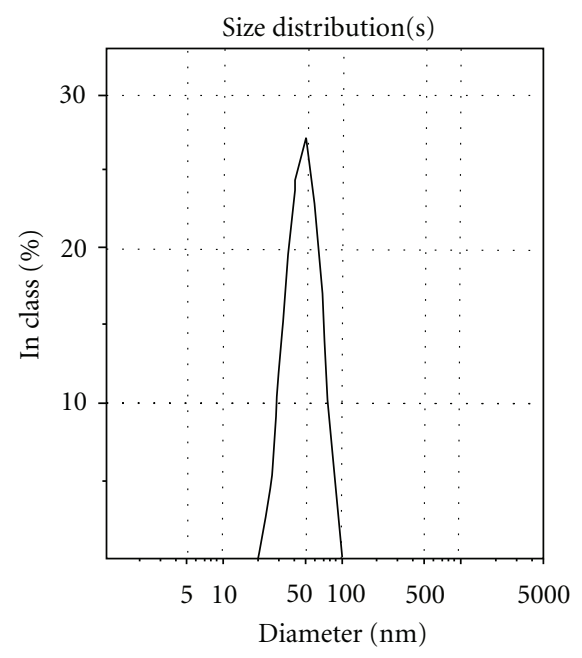

(c)

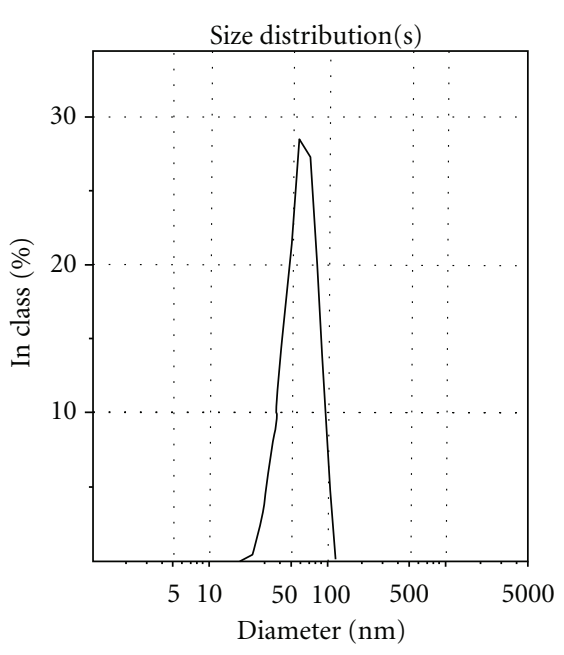

(d)

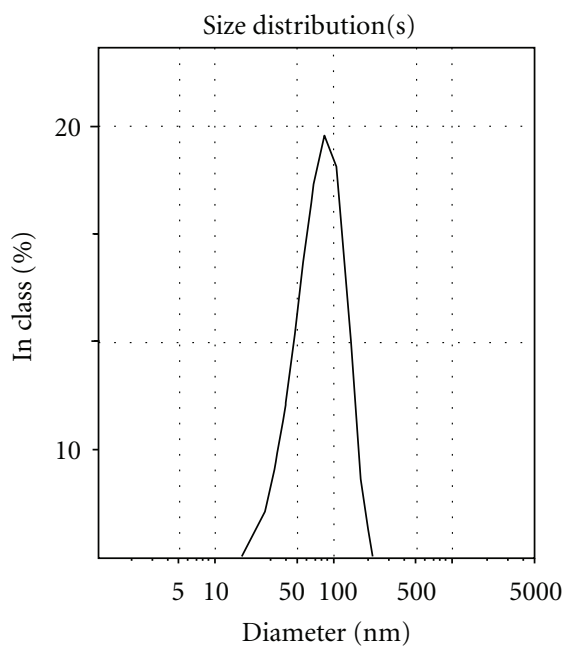

(e)

Figure 5: Particle size distributions of curcumin-loaded lipid nanoemulsions in formulations 1(a), 5(b) to 8(e).

3.4. Physical Stability Study. The time course-dependent change in the mean particle diameter of the lipid nanoemulsions prepared with 15,30 , and $60 \mathrm{mg}$ of curcumin during storage at $4^{\circ} \mathrm{C}$ for 60 days is presented in Figure 7. The mean particle diameters at day 60 were 54.9, 58.2, and $56.8 \mathrm{~nm}$, corresponding to 15,30 , and $60 \mathrm{mg}$ of curcumin applied. No significant changes due to dispersion instability were observed.

3.5. Effect of Curcumin-Loaded Nanoemulsionon Cytotoxicity. By using curcumin-loaded nanoemulsion prepared with formulation 5 (Table 1), the cytotoxic effects of the nanoemulsion at various concentrations $(0-67.86 \mu \mathrm{M}$ or $0-$ $25 \mu \mathrm{g} / \mathrm{mL}$ ) on B16F10, K562, Molt4, U937, and HL-60 cell lines for $48 \mathrm{~h}$ by MTT assay were investigated. The results are shown in Figure 8. Cucumin-loaded nanoemulsion is capable of inhibiting cell growth of all cell lines. The $\mathrm{IC}_{50}$ values (mean $\pm \mathrm{SE}$ ) of cucumin-loaded nanoemulsion treatment were $22.2 \pm 0.6,53.7 \pm 0.23,30.3 \pm 4.4,35.8 \pm 1.7$, and $23.5 \pm 1.1$, respectively, whereas the curcumin treatment were $3.5 \pm 0.5,38.7 \pm 2.0,14.4 \pm 2.3,30.1 \pm 0.9$, and $15.7 \pm$ $1.6 \mu \mathrm{M}$, respectively (Table 2 ). The $\mathrm{IC}_{50}$ value of curcuminloaded nanoemulsion is significantly different when compared to curcumin treatment in B16F10 cells $(P<0.05)$. However, four leukemic cell lines did not show different inhibitory effect between curcumin-loaded nanoemulsion and curcumin treatments. The nanoemulsion control did not show any different cytotoxic effect on all cancer cells $\left(\mathrm{IC}_{50}\right.$ values $>67.86 \mu \mathrm{M})$.

3.6. In Vitro Release Kinetics of Curcumin-Loaded Nanoemulsion. The release kinetics of curcumin-loaded nanoemulsion prepared with formulation 5 (Table 1) demonstrated approximately a $25 \%$ release of curcumin from the nanoemulsion at $72 \mathrm{~h}$, when dispersed in $25 \%$ human serum containingphosphate buffer saline at $\mathrm{pH} 7.4$ (Figure 9). However, the release kinetics in phosphate buffer saline was $1.4 \%$ at $72 \mathrm{~h}$. 
TABLE 2: $\mathrm{IC}_{50}$ values $(\mu \mathrm{M})$ of curcumin and curcumin-loaded nanoemulsion on B16F10, K562, Molt4, U937, and HL-60 cell lines.

\begin{tabular}{|c|c|c|c|c|c|}
\hline \multirow{2}{*}{ Treatment } & \multicolumn{5}{|c|}{$\mathrm{IC}_{50}(\mu \mathrm{M})$} \\
\hline & B16F10 & K562 & Molt4 & U937 & HL-60 \\
\hline Curcumin & $3.5 \pm 0.5$ & $38.7 \pm 2.0$ & $14.4 \pm 2.3$ & $30.1 \pm 0.9$ & $15.7 \pm 1.6$ \\
\hline $\begin{array}{l}\text { Curcumin-loaded } \\
\text { nanoemulsion }\end{array}$ & $22.2 \pm 0.6^{*}$ & $53.7 \pm 0.23$ & $30.3 \pm 4.4$ & $35.8 \pm 1.7$ & $23.5 \pm 1.1$ \\
\hline Nanoemulsion control & $>67.9$ & $>67.9$ & $>67.9$ & $>67.9$ & $>67.9$ \\
\hline
\end{tabular}

Each value denotes the mean \pm SE of three independent experiments $(n=3)$.

* Significantly different from the curcumin $(P<0.05)$.

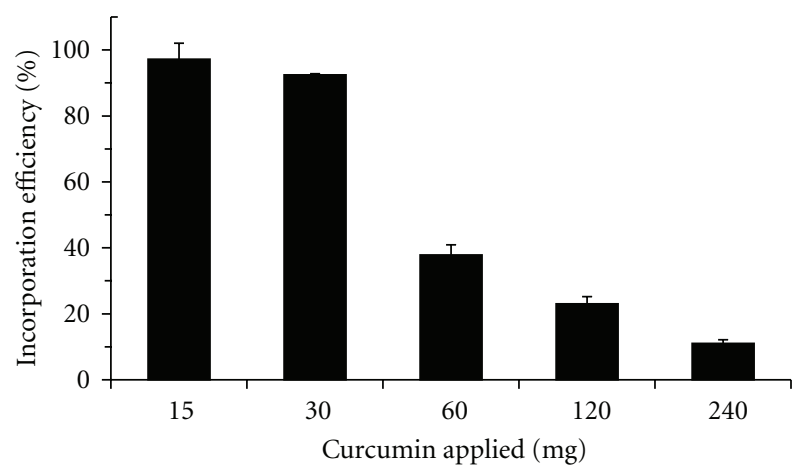

FIGURE 6: Effect of the amount of curcumin applied on the percent incorporation efficiency (\% IE) in formulations 1,5 to 8 . Data are the mean \pm standard deviation of 3 independent experiments $(n=$ $3)$.

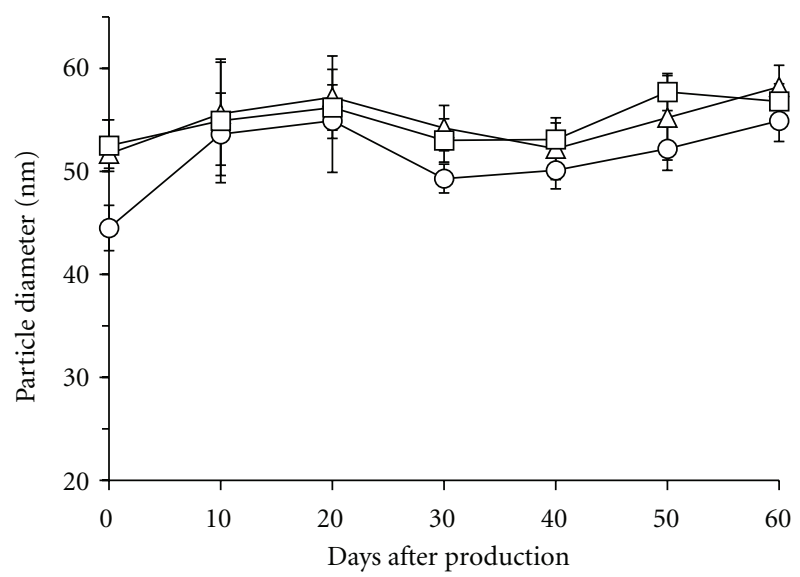

Figure 7: Physical stability of curcumin lipid emulsion in formulations 1,5 , and 6 during storage at $4^{\circ} \mathrm{C}$ for 60 days. Curcumin applied $(\mathrm{mg})$ : circle, 15; triangle, 30; square, 60. Data are represented as the mean \pm standard deviation of 3 independent experiments $(n=3)$.

\section{Discussion}

The criteria for designing curcumin-containing lipid nanoemulsions for cancer therapy were as follows: the particle diameter of the emulsion had to be smaller than $100 \mathrm{~nm}$ (50-90 nm); the curcumin content had to be as high as possible; the surface of the emulsions had to be modified with hydrophilic moieties to allow prolonged circulation in the blood.
Curcumin is a lipophilic molecule and exists in its enol-tautomer form (Figure 1). It exhibits limited solubility in water, slight solubility in methanol, and good solubility in DMSO and chloroform [34]. To overcome its limited water solubility, a number of new approaches have been investigated to deliver curcumin effectively by using lipid-based nanoparticulate carriers such as liposome encapsulation $[35,36]$. The formulation of the curcumin lipid nanoemulsion in this study was modified from the one used for the preparation of gadolinium-containing emulsions in the previous studies $[32,33]$. The main components of those emulsions were soybean oil, water, Gd-diethylenetriaminepentaacetic acid-distearylamine (GdDTPA-SA, a highly lipophilic compound), and HEPC. HCO60 was used as an effective co-surfactant, which could reduce the particle size and also enrich gadolinium in the nanoemulsion. Moreover, Tween 80 was also one of the effective co-surfactants to reduce the particle diameter to $52.7 \mathrm{~nm}$ in gadolinium-containing nanoemulsions, whereas it increased the particle diameter with increasing amounts of Gd-DTPA-SA in the nanoemulsion. Thus, this experiment was designed to study the effect of both HCO-60 and Tween 80 on particle size reduction and physical stability to identify the appropriate co-surfactant for curcumin lipid nanoemulsions.

A good emulsion was obtained in the preliminary experiments with HEPC. Hence, HEPC was selected as an emulsifier for curcumin-containing lipid nanoemulsions (Table 1). Then, the formulation and preparation conditions were optimized by changing the co-surfactant type, sonication time, and oil type. In order to evaluate the effect of co-surfactant and sonication time on the mean particle diameter of the lipid nanoemulsions, a series of samples were prepared with HCO-60 or Tween 80 as co-surfactant and soybean oil as oil component by increasing the sonication time at $15 \mathrm{mg}$ of the initial curcumin loading (formulations 1 to 4 , Table 1 ). The nanoemulsions were prepared at an HEPC-to-co-surfactant weight ratio of $1: 1.5$. Thus, the outer monolayer of the oil core in the lipid nanoemulsions would be composed of a HEPC-to-HCO-60 molar ratio of 7.6:2.4 or an HEPC-to-Tween 80 molar ratio of 5.4:4.6, assuming that all surfactant molecules were arranged on the interface of the oil core and water.

The sonication was effective to reduce the particle size of the nanoemulsions. In case of the Gd-DTPA-SA emulsion study, the particle diameter was gradually reduced by prolonging the sonication time $[32,33]$, leading to a decrease in 


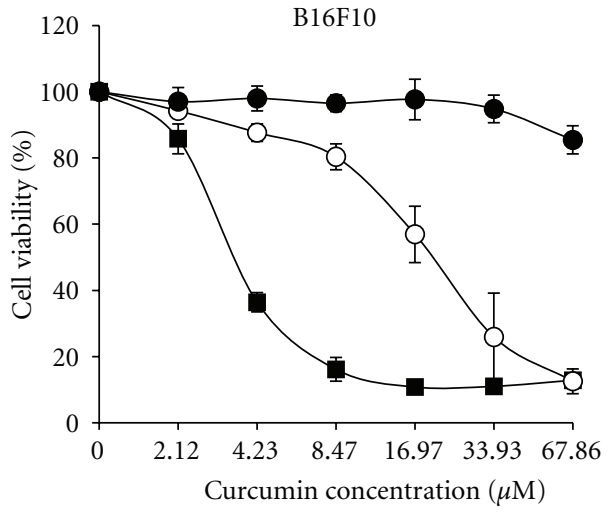

(a)

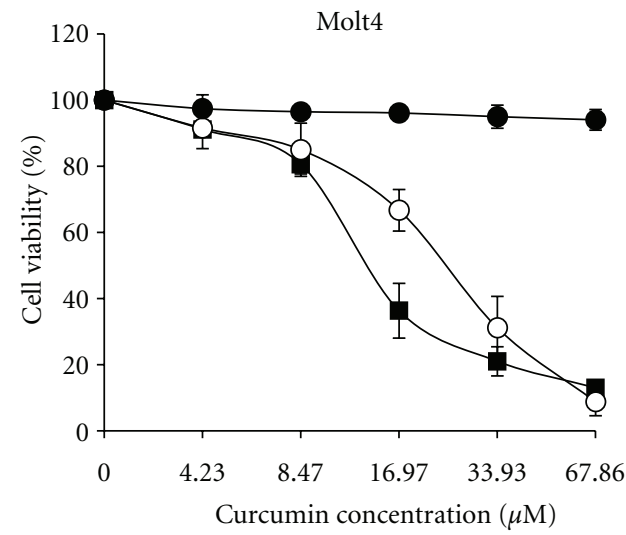

(c)

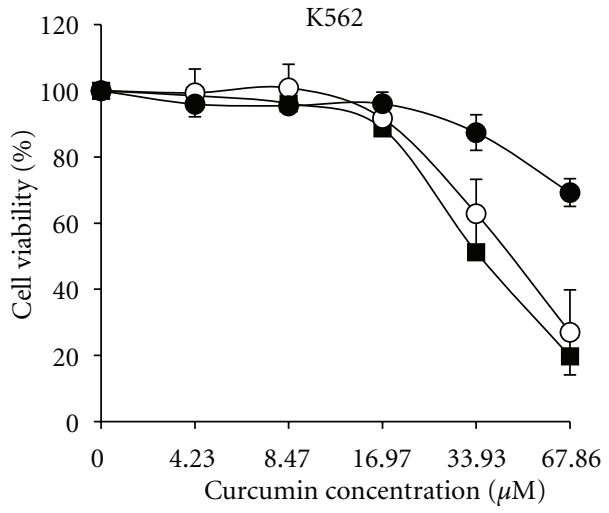

(b)

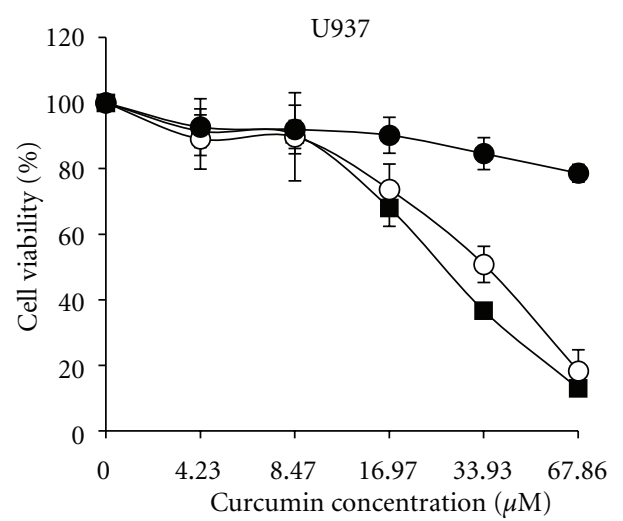

(d)

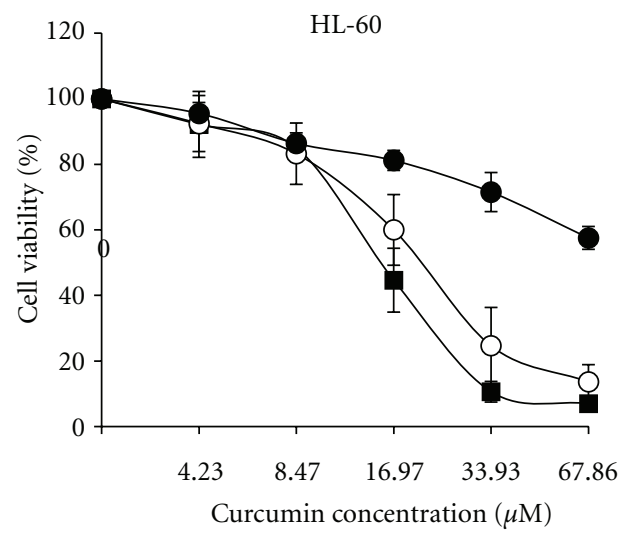

- Curcumin
- Curcumin-loaded nanoemulsion
- Nanoemulsion control

(e)

FIGURE 8: Cytotoxicity of curcumin and curcumin-loaded nanoemulsionon B16F10, K562, Molt4, U937, and HL-60 cell lines. $\mathbf{\square}$ : curcumin treatment, $\bigcirc$ : curcumin-loaded nanoemulsion, @: nanoemulsion control. Data are the mean \pm standard error (SE) of three independent experiments $(n=3)$.

the diameter from 306 to $239 \mathrm{~nm}$ within $2 \mathrm{~h}$. In the present study, 30 min sonication could rapidly decrease the particle diameter of the lipid nanoemulsions (Figure 2).

In this study, Tween 80 and HCO-60 were selected because they were effective co-surfactants in terms of particle size reduction in Gd-DTPA-SA-containing nanoemulsions $[32,33]$. The present results showed that emulsion particles using Tween 80 were much smaller than those using HCO60 (Figure 2). Thus, Tween 80 was selected to be the cosurfactant in our further studies. Nevertheless, both Tween 


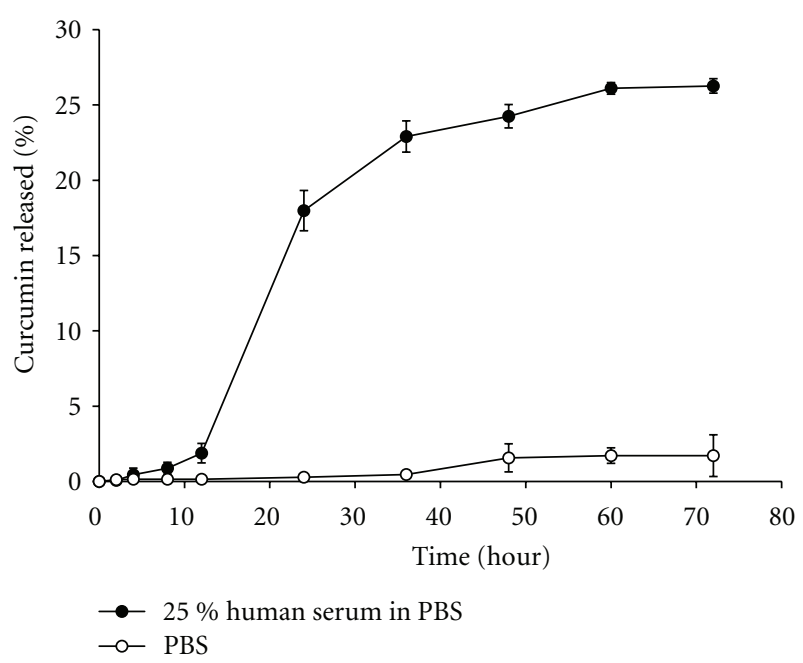

FIGURE 9: In vitro release kinetics of curcumin-loaded nanoemulsion. ๑: $25 \%$ Human serum in PBS, $\bigcirc$ : PBS.

80 and HCO-60 have been commonly used as stabilizers in commercially available lipid emulsion preparations for a long period of time $[37,38]$. Thus, they can possibly be used as co-surfactants in curcumin nanoemulsions because they provided the curcumin emulsions with a particle diameter small enough for long-term circulation in the blood and also to extravasate through blood capillaries in tumors.

Soybean oil and lecithin obtained from soybean were examined as oil components. Both oil types have been widely used as a model system for lipid emulsion studies and are generally used for commercially available fat emulsions. In general, the formula of intralipid was made of $10-30 \% \mathrm{w} / \mathrm{w}$ soybean oil and 1.2\% w/w lecithin. Lecithin also comes from soybean oil products. The amount of phospholipids in soybean oil and lecithin is $1.48-3.08 \%$ and $28.9-44.1 \%$, respectively [39]. However, the viscosities of soybean oil and lecithin are $69 \mathrm{mPa} \cdot \mathrm{s}$ and $10000 \mathrm{mPa} \cdot \mathrm{s}$, respectively, at $24^{\circ} \mathrm{C}$. In this study, the curcumin nanoemulsion with soybean oil showed smaller particle diameters than that with lecithin (Figure 3(a)). This difference in the particle diameter can be attributed to the lower viscosity of soybean oil: it can allow breakup of the oil droplets readily by the sonic wave generated from the ultrasonication treatment and thus possibly allow to form the smaller-sized nanoemulsion [32].

The \% IE of the curcumin lipid nanoemulsion was markedly decreased by the increasing total amount of curcumin applied (Figure 6), thereby implying that there were excess amounts of free curcumin after the emulsifying process. This result indicated that the lipid nanoemulsions were limited in their capacity to incorporate curcumin. Compared to the loading amount of curcumin in liposomes in the previous report [25], our formulation exhibited an 8-fold higher loading amount of curcumin.

According to solubility test based on formulation 5 (Table 1), the value of solubility of curcumin in $30 \mathrm{~mL}$ of Tween 80 -HEPC $(0.375 \mathrm{~g}$ and $0.250 \mathrm{~g}$ in $30 \mathrm{~mL}$ distilled water) aqueous solution was $20.5 \pm 1.4 \mathrm{mg}$ while that in

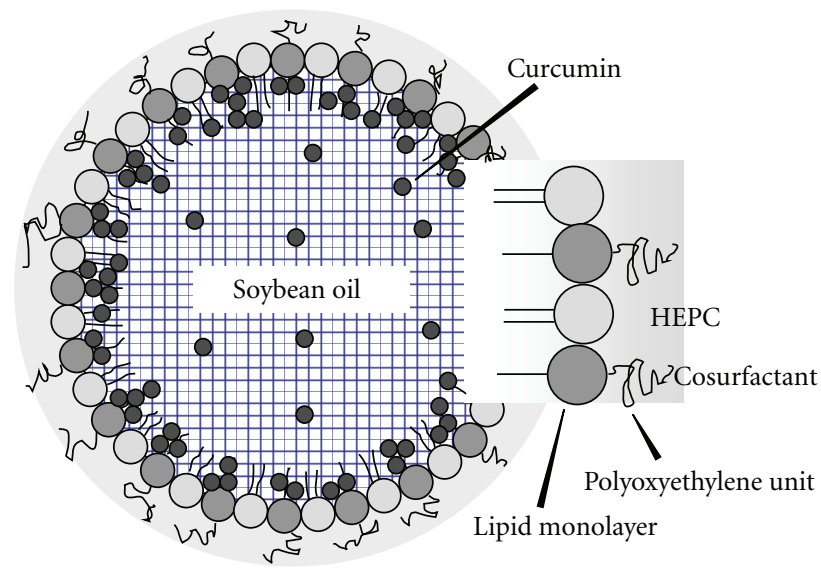

FIGURE 10: Schematic drawing of the particle structure of the curcumin-loaded lipid nanoemulsion.

$1 \mathrm{~mL}$ of soybean oil was confirmed to be $2.4 \mathrm{mg}$. Thus, it would be reasonable to consider that curcumin could be well solubilized in part of surfactant-phospholipid layer of the nanoemulsion rather than in soybean oil core particles. As shown in Figure 6, the amounts of curcumin incorporated in the emulsions prepared with formulations 5 to 8 were calculated as $27.7,22.7,27.6$, and $26.4 \mathrm{mg}$ for $30,60,120$, and $240 \mathrm{mg}$ of curcumin applied, respectively. These values agreed well with the value estimated from the solubility data $(22.9 \mathrm{mg}$ in total), suggesting that approximately $90 \%$ of curcumin incorporated in the emulsion might exist in the surface phospholipid-surfactant monolayer of the oil core particles. This might allow us to draw a possible structural scheme of the lipid nanoemulsion incorporating curcumin (Figure 10).

The anticancer properties of curcumin-loaded nanoemulsion, using mouse melanoma and leukemic cell lines as an experimental model system, and directly comparing its activities to curcumin were investigated. As demonstrated in Table 2, the curcumin-loaded nanoemulsion showed cytotoxicities to all cancer cells. The $\mathrm{IC}_{50}$ values were ranged from 22.2 to $53.7 \mu \mathrm{M}$. However, curcumin-loaded nanoemulsion exhibited higher cytotoxic effects in B16F10 than those of leukemic cells and showed the significant difference when compared to curcumin treatment. This might be the reason of the difference in cell phenotype that B16F10 is fibroblast cell and obtained from mouse. The B16F10 cell itself was more sensitive to curcumin than leukemic cell lines with the $\mathrm{IC}_{50}$ value of $3.5 \mu \mathrm{M}$. There were no significant difference of curcumin-loaded nanoemulsion and curcumin in four leukemic cell lines. Nevertheless, curcumin-loaded nanoemulsion showed lower cytotoxic effects on mouse melanoma and slightly lower on human leukemic cells possibly due to the limited availability of curcumin by slow and uncompleted release of curcumin from the nanoemulsion particles within 24 to $72 \mathrm{~h}$. The result is in parallel to the cytotoxicity of polymeric nanoparticleencapsulated curcumin (nanocurcumin) in pancreatic XPA1 cell line with the $\mathrm{IC}_{50}$ value of $\sim 20 \mu \mathrm{M}$ [24]. Inhibitory effect of liposomal curcumin $(5-10 \mu \mathrm{M})$ for $24-48 \mathrm{~h}$ on 
human prostate cancer cell lines ( $\mathrm{LNCaP}$ and $\mathrm{C} 42 \mathrm{~B})$ resulted in at least $70-80 \%$ inhibition of cellular proliferation without affecting cell viability [25]. In comparison to nanoemulsion control, it was much less cytotoxic on cancer cells. There was a report that showed that the surfactants themselves can influence MTT assay [40]. However, concentration of Tween 80 in nanoemulsion of this experiment did not affect cell cytotoxicity as shown in Figure 8 . Taken together, the activity of curcumin after incorporation into nanoemulsion seems to be determined by the curcumin release kinetics and the stability in activity on cancer cells.

\section{Conclusions}

This study showed the successful production of a curcumin lipid nanoemulsion with small particle size at a high yield. The curcumin lipid nanoemulsion was prepared by the thinlayer hydration method in a bath-type sonicator. The use of Tween 80 in the lipid nanoemulsion formulation instead of HCO-60 used previously resulted in a small particle size. The particle diameter of the lipid emulsion was decreased to $47-56 \mathrm{~nm}$ with small polydispersity. When increasing amounts of curcumin were added, the amount of curcumin incorporated in the emulsion was saturated. Approximately $90 \%$ of curcumin in the nanoemulsion was estimated to be in the surface layer of the oil core particles. Through the present study, an appropriate formulation for producing curcumin lipid nanoemulsions was found to be $1 \mathrm{~mL}$ soybean oil, $30 \mathrm{mg}$ of cucumin, $250 \mathrm{mg}$ of HEPC, $375 \mathrm{mg}$ of Tween 80 , and $30 \mathrm{~mL}$ of water. This formulation resulted in a curcuminloaded lipid nanoemulsion stable in size for 60 days at $4^{\circ} \mathrm{C}$. The results from the cytotoxicity test provide a strong evidence for curcumin-loaded nanoemulsion as effective nanodelivery vehicles that present the bioavaialbility of curcumin. Moreover, we demonstrated the noncytotoxicity of the nanoemulsion formulation in vitro, underscoring the potential of this nanoparticle as a carrier for hydrophobic drugs.

\section{Acknowledgments}

A part of this work was supported by the Matsumae International Foundation (MIF), Japan, the Thailand Government Budget, and National Research Council of Thailand (NRC).

\section{References}

[1] M. L. Kuo, T. S. Huang, and J. K. Lin, "Curcumin, an antioxidant and anti-tumor promoter, induces apoptosis in human leukemia cells," Biochimica et Biophysica Acta, vol. 1317, no. 2, pp. 95-100, 1996.

[2] R. Selvam, L. Subramanian, R. Gayathri, and N. Angayarkanni, "The anti-oxidant activity of turmeric (Curcuma longa)," Journal of Ethnopharmacology, vol. 47, no. 2, pp. 59-67, 1995.

[3] Sreejayan and M. N. A. Rao, "Curcuminoids as potent inhibitors of lipid peroxidation," Journal of Pharmacy and Pharmacology, vol. 46, no. 12, pp. 1013-1016, 1994.

[4] H. P. Ammon, N. H. Safayhi, T. Mack, and J. Sabieraj, "Mechanism of antiinflammatory actions of curcumine and boswellic acids," Journal of Ethnopharmacology, vol. 38, no. 23, pp. 113-119, 1993.

[5] A. Banerjee and S. S. Nigam, "Antimicrobial efficacy of the essential oil of Curcuma longa," Indian Journal of Medical Research, vol. 68, no. 5, pp. 864-866, 1978.

[6] S. T. N. Bhavani and M. V. Sreenivasa, "Effect of turmeric (Curcuma longa) fractions on the growth of some intestinal \& pathogenic bacteria in vitro," Indian Journal of Experimental Biology, vol. 17, no. 12, pp. 1363-1366, 1979.

[7] T. Sawada, J. Yamahara, S. Shimazu, and T. Ohta, "Evaluation of crude drugs by bioassay. III. Comparison with local variation of contents and the fungistatic action of essential oil from the root of Curcuma longa," Shoyakugaku Zasshi, vol. 25, no. 1, pp. 11-16, 1971.

[8] D. S. Rao, N. C. Sekhara, M. N. Satyanarayana, and M. Srinivasan, "Effect of curcumin on serum and liver cholesterol levels in the rat," Journal of Nutrition, vol. 100, no. 11, pp. 1307-1315, 1970.

[9] P. Limtrakul, S. Anuchapreeda, S. Lipigorngoson, and F. W. Dunn, "Inhibition of carcinogen induced c-Ha-ras and cfos proto-oncogenes expression by dietary curcumin," BMC Cancer, vol. 1, no. 1, article 1, pp. 1-7, 2001.

[10] S. Anuchapreeda, P. Limtrakul, P. Thanarattanakorn, S. Sittipreechacharn, and P. Chanarat, "Inhibitory effect of curcumin on WT1 gene expression in patient leukemic cells," Archives of Pharmacal Research, vol. 29, no. 1, pp. 80-87, 2006.

[11] S. Anuchapreeda, P. Thanarattanakorn, S. Sittipreechacharn, P. Chanarat, and P. Limtrakul, "Curcumin inhibits WT1 gene expression in human leukemic K562 cells," Acta Pharmacologica Sinica, vol. 27, no. 3, pp. 360-366, 2006.

[12] S. Anuchapreeda, S. Tima, C. Duangrat, and P. Limtrakul, "Effect of pure curcumin, demethoxycurcumin, and bisdemethoxycurcumin on WT1 gene expression in leukemic cell lines," Cancer Chemotherapy and Pharmacology, vol. 62, no. 4, pp. 585-594, 2008.

[13] K. Polasa, T. C. Raghuram, T. Prasanna Krishna, and K. Krishnaswamy, "Effect of turmeric on urinary mutagens in smokers," Mutagenesis, vol. 7, no. 2, pp. 107-109, 1992.

[14] R. G. Roy, N. M. Madesayaa, and R. B. Ghosh, "Study on inhalation therapy by an indigenous compound on $P$. vivax and P. falciparum infections: a preliminary communication," Indian Journal of Medical Research, vol. 64, no. 10, pp. 14511455, 1976.

[15] M. A. Azuine and S. V. Bhide, "Chemopreventive effect of turmeric against stomach and skin tumors induced by chemical carcinogens in Swiss mice," Nutrition and Cancer, vol. 17, no. 1, pp. 77-83, 1992.

[16] T. Dorai, Y. C. Cao, B. Dorai, R. Buttyan, and A. E. Katz, "Therapeutic potential of curcumin in human prostate cancer. III. Curcumin inhibits proliferation, induces apoptosis, and inhibits angiogenesis of LNCaP prostate cancer cells in vivo," Prostate, vol. 47, no. 4, pp. 293-303, 2001.

[17] S. Anuchapreeda, R. Muangmoonchai, and P. Limtrakul, "Effect of curcuminoids on MDR1 gene promoter activity in human cervical carcinoma cells," Chiang Mai Medical Bulletin, vol. 41, no. 4, pp. 189-202, 2002.

[18] T. N. Bhavani Shankar, N. V. Shantha, and H. P. Ramesh, "Toxicity studies on turmeric (Curcuma longa): acute toxicity studies in rats, guinea pigs and monkeys," Indian Journal of Experimental Biology, vol. 18, no. 1, pp. 73-75, 1980.

[19] P. Limtrakul, W. Chearwae, and S. Anuchapreeda, "The effect of curcumin on the proliferation of cancer cell lines," Chiang Mai Medical Bulletin, vol. 38, no. 3-4, pp. 55-61, 1999. 
[20] S. Anuchapreeda, W. Sadjapong, C. Duangrat, and P. Limtrakul, "The cytotoxic effect of curcumin, demethoxycurcumin and bisdemethoxycurcumin purified from Turmeric powder on leukemic cell lines," Bulletin of Chiang Mai Associated Medical Sciences, vol. 39, no. 1, pp. 60-71, 2006.

[21] S. Semsri, S. R. Krig, L. Kotelawala, C. A. Sweeney, and S. Anuchapreeda, "Inhibitory mechanism of pure curcumin on Wilms' tumor 1 (WT1) gene expression through the PKC $\alpha$ signaling pathway in leukemic K562 cells," FEBS Letters, vol. 585, no. 14, pp. 2235-2242, 2011.

[22] T. M. Allen, C. Hansen, and J. Rutledge, "Liposomes with prolonged circulation times: factors affecting uptake by reticuloendothelial and other tissues," Biochimica et Biophysica Acta, vol. 981, no. 1, pp. 27-35, 1989.

[23] Y. Kato, K. Watanabe, M. Nakakura, T. Hosokawa, E. Hayakawa, and K. Ito, "Blood clearance and tissue distribution of various formulations of $\alpha$-tocopherol injection after intravenous administration," Chemical and Pharmaceutical Bulletin, vol. 41, no. 3, pp. 599-604, 1993.

[24] S. Bisht, G. Feldmann, S. Soni et al., "Polymeric nanoparticleencapsulated curcumin ("nanocurcumin"): a novel strategy for human cancer therapy," Journal of Nanobiotechnology, vol. 5, article 3, pp. 1-18, 2007.

[25] R. L. Thangapazham, A. Puri, S. Tele, R. Blumenthal, and R. K. Maheshwari, "Evaluation of a nanotechnology-based carrier for delivery of curcumin in prostate cancer cells," International Journal of Oncology, vol. 32, no. 5, pp. 1119-1123, 2008.

[26] R. K. Das, N. Kasoju, and U. Bora, "Encapsulation of curcumin in alginate-chitosan-pluronic composite nanoparticles for delivery to cancer cells," Nanomedicine, vol. 6, no. 1, pp. e153-e160, 2010.

[27] J. J. Wheeler, K. F. Wong, S. M. Ansell, D. Masin, and M. B. Bally, "Polyethylene glycol modified phospholipids stabilize emulsions prepared from triacylglycerol," Journal of Pharmaceutical Sciences, vol. 83, no. 11, pp. 1558-1564, 1994.

[28] F. Liu and D. Liu, "Long-circulating emulsions (oil-in-water) as carriers for lipophilic drugs," Pharmaceutical Research, vol. 12, no. 7, pp. 1060-1064, 1995.

[29] A. Kurihara, Y. Shibayama, A. Mizota et al., "Lipid emulsions of palmitoylrhizoxin: effects of composition on lipolysis and biodistribution," Biopharmaceutics and Drug Disposition, vol. 17, no. 4, pp. 331-342, 1996.

[30] Y. Wang, G. M. Mesfin, C. A. Rodríguez et al., "Venous irritation, pharmacokinetics, and tissue distribution of tirilazad in rats following intravenous administration of a novel supersaturated submicron lipid emulsion," Pharmaceutical Research, vol. 16, no. 6, pp. 930-938, 1999.

[31] R. C. Marãnhao, B. Garicochea, E. L. Silva et al., "Plasma kinetics and biodistribution of a lipid emulsion resembling low- density lipoprotein in patients with acute leukemia," Cancer Research, vol. 54, no. 17, pp. 4660-4666, 1994.

[32] M. Miyamoto, K. Hirano, H. Ichikawa, Y. Fukumori, Y. Akine, and K. Tokuuye, "Preparation of gadolinium-containing emulsions stabilized with phosphatidylcholine-surfactant mixtures for neutron-capture therapy," Chemical and Pharmaceutical Bulletin, vol. 47, no. 2, pp. 203-208, 1999.

[33] M. Miyamoto, K. Hirano, H. Ichikawa, Y. Fukumori, Y. Akine, and K. Tokuuye, "Biodistribution of gadolinium incorporated in lipid emulsions intraperitoneally administered for neutroncapture therapy with tumor-bearing hamsters," Biological and Pharmaceutical Bulletin, vol. 22, no. 12, pp. 1331-1340, 1999.

[34] F. Payton, P. Sandusky, and W. L. Alworth, "NMR study of the solution structure of curcumin," Journal of Natural Products, vol. 70, no. 2, pp. 143-146, 2007.
[35] L. Li, F. S. Braiteh, and R. Kurzrock, "Liposome-encapsulated curcumin: in vitro and in vivo effects on proliferation, apoptosis, signaling, and angiogenesis," Cancer, vol. 104, no. 6, pp. 1322-1331, 2005.

[36] K. Maiti, K. Mukherjee, A. Gantait, B. P. Saha, and P. K. Mukherjee, "Curcumin-phospholipid complex: preparation, therapeutic evaluation and pharmacokinetic study in rats," International Journal of Pharmaceutics, vol. 330, no. 1-2, pp. 155-163, 2007.

[37] C. F. Hung, T. L. Hwang, C. C. Chang, and J. Y. Fang, "Physicochemical characterization and gene transfection efficiency of lipid emulsions with various co-emulsifiers," International Journal of Pharmaceutics, vol. 289, no. 1-2, pp. 197-208, 2005.

[38] A. Chinsriwongkul, P. Opanasopit, T. Ngawhirunpat, N. Chareansriwilaiwat, W. Sila-On, and U. Ruktanonchai, "Physicochemical properties of lipid emulsions formulated with highload all-trans-retinoic acid," PDA Journal of Pharmaceutical Science and Technology, vol. 61, no. 6, pp. 461-471, 2007.

[39] W. J. Hurstand and R. A. Martin Jr., "The analysis of phospholipids in soy lecithin by HPLC," Journal of American Oil Chemists' Society, vol. 61, no. 9, pp. 1462-1463, 1984.

[40] Y. Li, S. Le Maux, H. Xiao, and D. J. McClements, "Emulsionbased delivery systems for tributyrin, a potential colon cancer preventative agent," Journal of Agricultural and Food Chemistry, vol. 57, no. 19, pp. 9243-9249, 2009. 

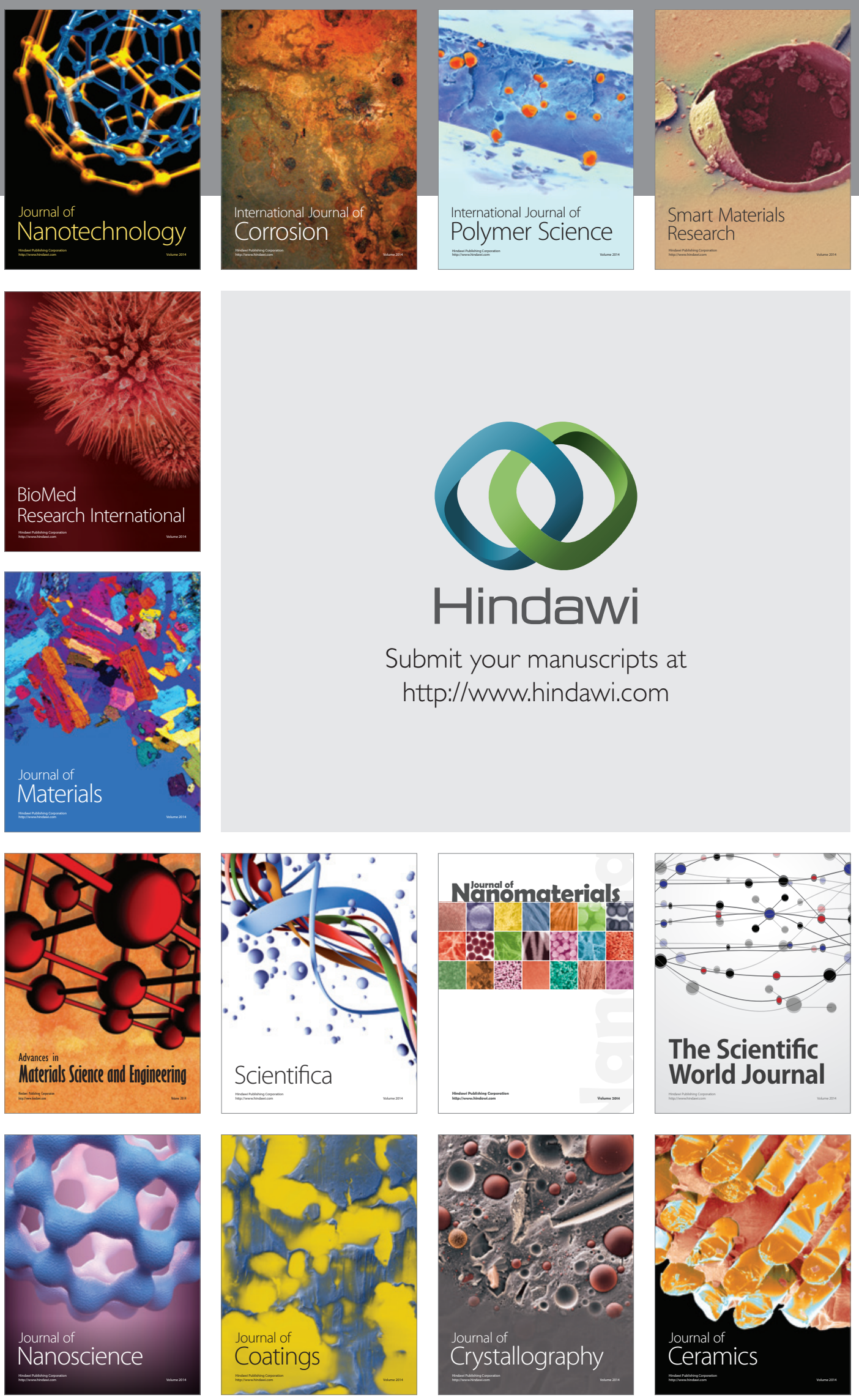

The Scientific World Journal

Submit your manuscripts at

http://www.hindawi.com

\section{World Journal}

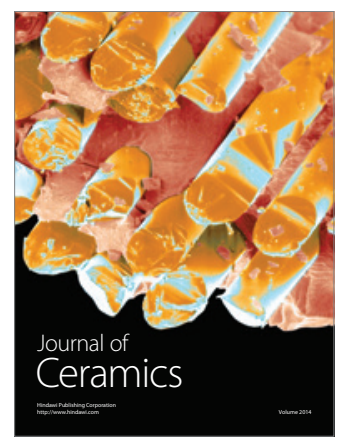

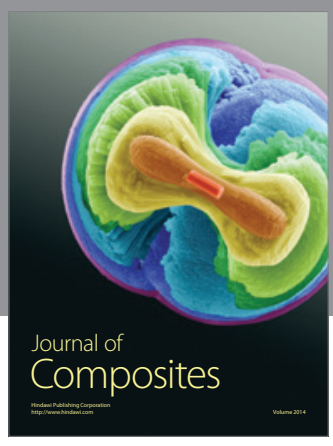
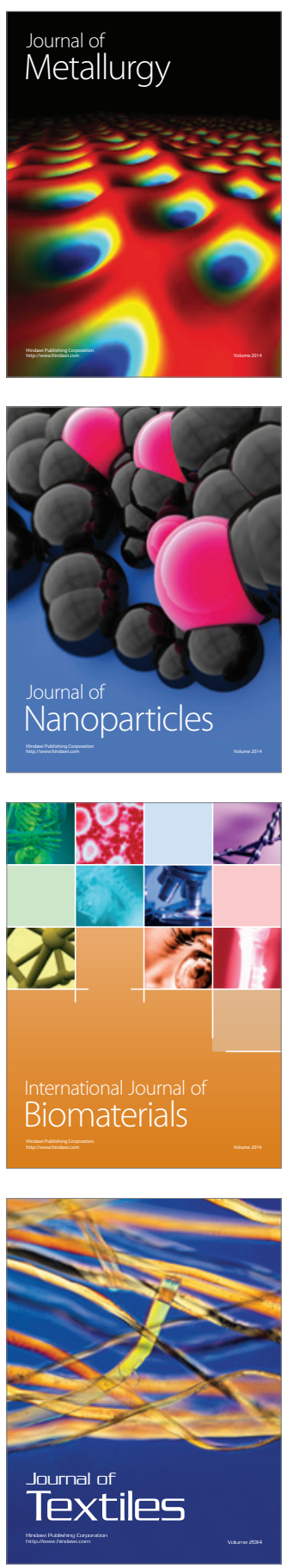